\title{
Reply to: Late-stage Parkinson's disease: the Barcelona and Lisbon cohorts. Past phenomenology and today's clinical needs
}

\author{
Miguel Coelho
}

Received: 27 October 2010/ Accepted: 28 October 2010/Published online: 19 November 2010

(C) Springer-Verlag 2010

Dear Sirs,

We thank Dr. S.G. Echebarria for his comments on our study exploring the clinical characteristics of Parkinson's disease patients in late-stage.

Dr. S.G. Echebarria discusses how our data can add information regarding disease disability and natural history of disease, commenting on the clinical thresholds to start symptomatic treatment observed in two large cohort studies, DATATOP and PRECEPT [1].

In fact, the cross-sectional design of our study limits any conclusion regarding the progression of disability in later stages of Parkinson's disease. Nevertheless, our results show that the symptoms contributing most to disability are non-levodopa responsive, either motor or non-motor, and that dementia is not inevitable in the later stages of Parkinson's disease. This evidence is important to plan healthcare interventions in the later stages of Parkinson's disease.

\section{Reference}

1. Marras C, Lang A, Eberly S et al (2009) A comparison of treatment thresholds in two large PD clinical trial cohorts. Mov Disord 24(16):2370-2378

M. Coelho $(\bowtie)$

Neurological Clinical Research Unit, Instituto de Medicina

Molecular, Hospital Santa Maria, Lisbon, Portugal

e-mail: migcoelho2002@yahoo.es 